\title{
ВЛИЯНИЕ РАЗЛИЧНЫХ ВАРИАНТОВ КОМПЛЕКСОВ ОЗДОРОВИТЕЛЬНЫХ УПРАЖНЕНИЙ НА ФИЗИЧЕСКУЮ ПОДГОТОВЛЕННОСТЬ МАЛЬЧИКОВ 13-14 ЛЕТ
}

\section{INFLUENCE OF DIFFERENT VARIANTS OF WELLNESS EXERCISES ON THE PHYSICAL READINESS OF 13-14 YEARS OLD BOYS \\ V. Sukhetski}

Summary: The article presents experimental data on the influence of various health-improving programs of physical exercises on the level of motor readiness of 13-14-year-old boys, 2 and 3 stages of puberty. The following were used as regulated pedagogical factors in the work: load intensity, load duration, frequency of classes, orientation and weekly load volume. In the course of experimental studies, the range of the weekly value of physical activity and the predominant orientation of physical exercises, providing an increase in the physical fitness of adolescents, were determined. It was found that the most effective was the program of physical exercises of predominantly anaerobic orientation with a weekly volume of physical activity of 120 minutes, which to a somewhat greater extent contributes to the growth of the physical potential of adolescents. The results obtained can find application in the physical education of adolescents.

Keywords: boys, adolescents, physical fitness, physical exercises, load intensity, load direction, load duration, weekly load volume, number of sessions.
Сухецкий Валерий Константинович

Дочент, УО «Гродненский государственный университет имени Янки Купалы»

vsukhetski@mail.ru

Аннотация: В статье представлены экспериментальные данные о влиянии различных оздоровительных программ физических упражнений на уровень двигательной подготовленности мальчиков 13-14 лет, 2 и 3 стадии полового созревания. В качестве регулируемых педагогических факторов в работе использовались: интенсивность нагрузки, продолжительность нагрузки, кратность занятий, направленность и недельный объем нагрузки. В ходе экспериментальных исследований определен диапазон недельной величины физической нагрузки и преимущественная направленность физических упражнений, обеспечивающие повышение физической подготовленности подростков. Установлено что наиболее эффективной оказалась программа физических упражнений преимущественно анаэробной направленности с недельным объемом физической нагрузки 120 мин, которая в несколько большей степени способствует росту физического потенциала подростков. Полученные результаты могут найти применение в физическом воспитании подростков.

Ключевые слова: мальчики, подростки, физическая подготовленность, физические упражнения, интенсивность нагрузки, направленность нагрузки, продолжительность нагрузки, недельный объем нагрузки, количество занятий.

Целью данного исследования являлось изучение влияния различных вариантов комплексов оздоровительных упражнений на физическую подготовленность мальчиков 13-14 лет.

В педагогическом эксперименте изучалась годовая динамика физической подготовленности подростков 13-14 лет. Оценивалось проявление силовых (становая динамометрия, подтягивание в висе на перекладине, поднимание туловища из положения лежа на спине), скоростных (челночный бег 4x9 м, бег 20 м с хода), скоростно-силовых способностей (прыжок в длину с места), гибкости (наклон вперед) и общей выносливости (бег 6 мин). В исследовании принимали участие 120 мальчиков (средний возраст 13,5 0,4 года, II и III стадии полового созревания) 7 классов.

В качестве регулируемых педагогических факторов использовались: интенсивность нагрузки, продолжительность нагрузки, кратность занятий, направленность и недельный объем нагрузки (табл. 1). 
Таблица 1.

Распределение компонентов физической нагрузки в педагогическом эксперименте

\begin{tabular}{|c|c|c|c|c|c|}
\hline \multirow{2}{*}{ Группы } & \multirow{2}{*}{$\begin{array}{c}\text { Направленность на- } \\
\text { грузки }\end{array}$} & \multicolumn{2}{|c|}{ Количество занятий } & \multicolumn{2}{|c|}{ Недельный объем } \\
\hline & & в неделю & всего & эксперим. & общий \\
\hline ЭГ-1 & аэробная & 3 & 102 & 60 мин & 135 мин \\
\hline ЭГ-2 & аэробная & 6 & 204 & 120 мин & 315 мин \\
\hline ЭГ-З & анаэробная & 3 & 102 & 60 мин & 135 мин \\
\hline ЭГ-4 & анаэробная & 6 & 204 & 120 мин & 315 мин \\
\hline ЭГ-5 & аэробная и анаэробная & 3 & 102 & 120 мин & 135 мин \\
\hline ЭГ-6 & аэробная и анаэробная & 6 & 204 & 240 мин & 315 мин \\
\hline ЭГ-7 & & 6 & 204 & - & 315 мин \\
\hline КГ & & 3 & 102 & - & 135 мин \\
\hline
\end{tabular}

Результаты, полученные в ходе педагогического эксперимента, обрабатывались с помощью общепринятых методов статистики. Достоверность различий оценивалась с помощью параметрических и непараметрических критериев для корреляционно независимых выборок.

В ходе формирующего педагогического эксперимента подросткам предлагались физические нагрузки с низкой (40-50 \% максимального пульсового резерва) и высокой (70-80 \% максимального пульсового резерва) интенсивностью. В ЭГ1, ЭГ2, ЭГЗ, ЭГ4, ЭГ5, ЭГб интенсивность физической нагрузки была высокой, а в ЭГ7 и КГ - низкой.

После проведенного педагогического эксперимента были получены следующие результаты годовой динамики физической подготовленности. Измерение абсолютных показателей становой динамометрии показало, что наибольшие $(p<0,001)$ годовые сдвиги $29,75 \pm 2,72$ кг и

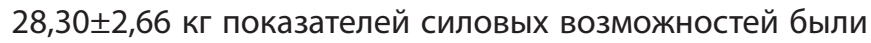
зафиксированы у испытуемых, занимающихся в группах с преимущественно анаэробной направленностью физической нагрузки объемом 120 мин в неделю (ЭГ4) и смешанной нагрузкой объемом 240 мин в недельном

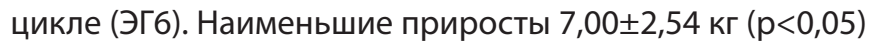
обнаружены в группе, занимающейся физической нагрузкой с низкой интенсивностью физической нагрузки объемом 120 мин в неделю (ЭГ7).

Аналогичные данные зафиксированы по результатам выполнения подтягивания в висе и поднимании туловища, где наибольшие сдвиги ( $<<0,001)$ были зафиксированы также у испытуемых преимущественно анаэробной группы (ЭГ4), занимающихся 120 мин в неделю (увели-

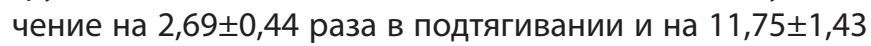
раза в поднимании туловища) и в группе подростков со смешанной направленностью физической нагрузки

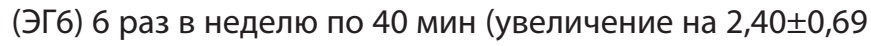

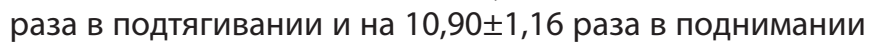
туловища). Наименьшие сдвиги (p>0,05) обнаружены в контрольной группе (КГ), занимающихся физической нагрузкой с низкой интенсивностью 3 раза в неделю на уроках физической культуры и здоровья - в подтягива-

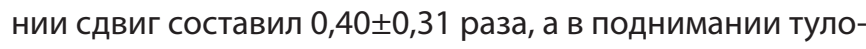

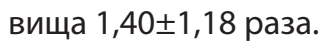

Относительный показатель становой динамометрии достоверно улучшился на 20-25\% (p<0,01-0,001) в группе с преимущественно анаэробной направленностью физической нагрузки с недельным объемом 120 мин (ЭГ4) и в группах со смешанной направленностью нагрузки недельным объемом 120 мин (ЭГ5) и 240 мин (ЭГб).

Полученные данные о степени развития силы у школьников различных опытных групп хорошо отражают направленность используемых комплексов физической подготовки. В тех группах, где использовались преимущественно упражнения анаэробной направленности (ЭГЗ и ЭГ4), а также упражнения с большим и повышенным недельным объемом смешанных нагрузок (ЭГ5 и ЭГб) обнаружились более высокие статистически значимые $(p<0,001)$ сдвиги силовых показателей. Менее значимые приросты данных показателей зафиксированы в группах испытуемых с преимущественно аэробной направленностью занятий (ЭГ1 и ЭГ2) и группах с низкой интенсивностью нагрузки (ЭГ7 и КГ), что, вероятно, является следствием недостаточного использования физических упражнений на развитие силы в процессе физического воспитания.

По показателю гибкости, оцениваемому по величине максимального сгибания тела, наиболее существенные сдвиги ( $<<0,001)$ продемонстрировали подростки преимущественно анаэробной группы, занимающиеся 6 раз в недельном цикле по 20 мин (ЭГ4) $6,63 \pm 0,92$ см. Достаточно высокий среднестатистический ( $<<0,01-0,001)$ прирост уровня гибкости обнаружен

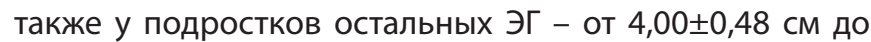

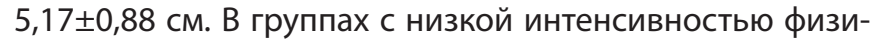
ческой нагрузки статистически значимого сдвига не об- 


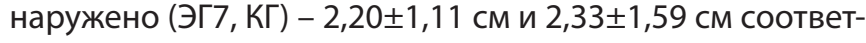
ственно. Подростки этих групп показали недостаточное увеличение уровня гибкости.

В оценке скоростно-силовых способностей (прыжок в длину с места) полученные данные мы выявили следующую картину. Первое место по величине годового прироста $(p<0,001)$ заняла группа с повышенным объемом физической нагрузки различной метаболической на-

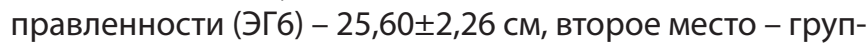
па с преимущественно анаэробной направленностью нагрузки 120 мин в неделю (ЭГ4) - 23,75 22,24 см, третье группа с большим объемом нагрузки смешанной на-

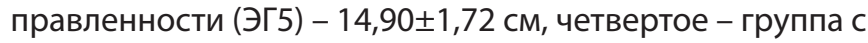
преимущественно аэробной направленностью физиче-

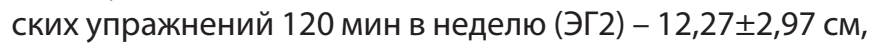
пятое - группа с анаэробной направленностью нагрузки

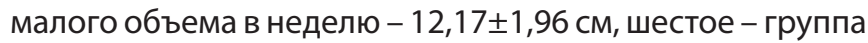
с аэробной направленностью упражнений общим объемом 60 мин в неделю - 11,62 22,37 см. Группы с низкой интенсивностью физической нагрузки объемом 60 и 120 мин в неделю заняли соответственно предпоследнее и последнее место, у них обнаружены менее существен-

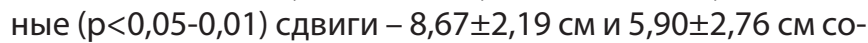
ответственно.

Результаты измерения уровня выносливости показали, что наибольшие сдвиги ( $p<0,001)$ показателей шестиминутного бега были у подростков, занимающихся физическими упражнениями преимущественно аэробной

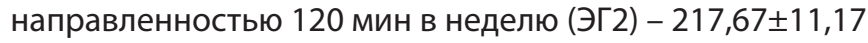

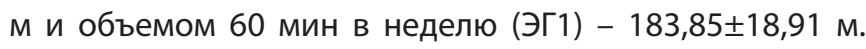
Наименьшие сдвиги ( $<<0,05)$ обнаружены у школьников, занимающихся физическими упражнениями низкой ин-

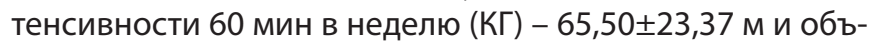

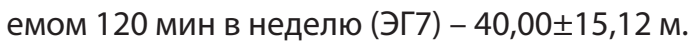

Уровень скоростных способностей оценивался по результатам бега на 20м с хода и челночного бега 4x9 м. Данные тестирования показали, что наиболее высокие приросты скорости $(p<0,001)$ произошли в группе с преимущественно анаэробной направленностью нагрузки объемом 120 мин в неделю (ЭГ4), результаты улучшились на 0,38 0,04 сек и 0,73 $\pm 0,07$ сек соответственно и в группе с повышенным объемом нагрузки смешанной направ-

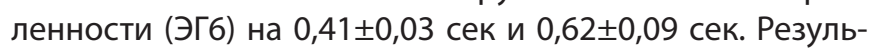
таты бега на 20м в группе подростков, занимающихся преимущественно аэробными физическими упражнениями с недельным объемом 60 мин (ЭГ1) и в группе испытуемых с низкой интенсивностью физической нагрузки с недельным объемом 60 мин (КГ) статистически значимо не изменились. По результатам челночного бега достоверных изменений не обнаружено в КГ подростков.

Таким образом, уровень различных показателей физической подготовленности изменяется в зависимости от интенсивности, объема, кратности и направленности экспериментальной физической нагрузки. Физические нагрузки с высокой интенсивностью (70-80\% максимального пульсового резерва) содействуют значимому $(p<0,05-0,001)$ повышению физической подготовленности подростков 13-14 лет в сравнении с низкоинтенсивными занятиями физической культурой (40-50\% максимального пульсового резерва). Направленность физической нагрузки отразилась на результатах педагогических тестов. Преимущественно аэробная направленность физических нагрузок, способствовала наибольшим приростам показателей общей и силовой выносливости, в то время как преимущественно анаэробные упражнения, оказали влияние на высокие годовые сдвиги в уровне развития силовых и скоростных качеств. Физические упражнения смешанной направленности оказали влияние на рост всех показателей физической подготовленности. Увеличение недельного объема тренирующего воздействия разной направленности способствовало дальнейшему росту показателей физической подготовленности подростков экспериментальных групп.

У мальчиков 13-14 лет в КГ под влиянием нагрузок низкой интенсивности малого недельного объема (60мин) достоверно ( $<<0,05-0,01)$ улучшились показатели прыжка в длину с места, шестиминутного бега, становой динамометрии. Физические нагрузки низкой интенсивности большого недельного объема (120 мин) в ЭГ7 способствовали значительному улучшению результатов прыжка в длину с места, челночного бега, поднимания туловища, шестиминутного бега, становой динамометрии и общего балла физической подготовленности. Но статистически значимые $(p<0,05)$ различия между ЭГ7 и КГ обнаружены только по показателю челночного бега. Таким образом, увеличение объема физических нагрузок низкой интенсивности до 120 мин в неделю не вызывает значимых приростов показателей физической подготовленности.

Повышенный недельный объем (240 мин) физической нагрузки в ЭГб способствовал значимым приростам физической подготовленности ( $<<0,05-0,001)$ по показателям: челночного бега, бега на 20 м, прыжка в длину с места, шестиминутного бега, становой динамометрии, подтягивания в висе, поднимания туловища из положения лежа, наклона вперед. Подростки данной опытной группа (ЭГб) значительно отличались $(p<0,05-0,01)$ от мальчиков других экспериментальных групп по годовым приростам результатов в беге на 20 м и в шестиминутном беге (ЭГ1, ЭГ2, ЭГЗ, ЭГ4, ЭГ5), в челночном беге (ЭГ1, ЭГ2, ЭГ5), в поднимании туловища, в становой динамометрии и в прыжке в длину с места (ЭГ1, ЭГ2, ЭГЗ, ЭГ5), в подтягивания (ЭГ1, ЭГ2). Таким образом, увеличение объема высокоинтенсивных физических упражнений смешанной направленности до 240 мин в неделю, спо- 
собствует значительному росту физической подготовленности подростков 13-14 лет. В научной литературе имеются данные о том, что увеличение недельного объема физической нагрузки до 135 мин за счет введения одного дополнительного урока физической культуры в неделю с высокой интенсивностью существенно повышает физическую подготовленность школьников [2].

Шестиразовые занятия физическими упражнениями различной направленности по 20 мин (ЭГ2, ЭГ4), недельным объемом 120 мин, оказали существенный прирост $(p<0,05-0,01)$ показателей физической подготовленности подростков, в сравнении с опытными группами подростков, занимающихся 3 раза в неделю по 40 минут (ЭГ5). Что доказывает, что периодичность играет важную роль в нормировании физических нагрузок подростков 13-14 лет.

Наиболее высокий прирост (37\%) интегрального показателя физической подготовленности отмечен в группе подростков, занимающихся преимущественно анаэробными упражнения 6 раз в неделю по 20 мин. Полученные нами данные о том, что у мальчиков 13-14 лет тренирующие физические нагрузки анаэробной направленности вызывают более существенные сдвиги ( $<<0,05-0,001)$ физической подготовленности в сравнении с нагрузками аэробного характера, находятся в соответствии с результатами других научных работ [1, 8, $10,13]$. Данный фактор объясняется тем, что в период полового созревания увеличивается доля анаэробного гликолиза при выполнении физических нагрузок в зоне большой и максимальной мощности $[7,12]$. У мальчиков интенсивно увеличивается силовой потенциал мышечных волокон, по причине воздействия на них гормона тестостерона.

Таким образом, развитие скоростных и силовых физических качеств в данный период полового созревания (II, III CПC) может быть высокоэффективным для повышения уровня физической подготовленности подростков 13-14 лет. Наиболее эффективной оказалась программа высокоинтенсивных физических упражнений преимущественно анаэробной направленности с недельным объемом физической нагрузки 120 мин (6 раз в неделю по 20 мин), которая в несколько большей степени способствует росту физического потенциала подростков.

\section{ЛИТЕРАТУРА}

1. Безруких М.М. Возрастная физиология (Физиология развития) / М.М. Безруких, В.Д. Сонькин, Д.А. Фарбер. - М.: Издательский центр «Академия», 2003. $-416 \mathrm{C}$.

2. Зотова Ф.Р. Эффективность дополнительных «тренировочных» уроков физической культуры в инновационных школах / Ф.Р. Зотова // Физическая культура: воспитание, образование, тренировка. - 2004. - № 1. - С. 25.

3. Криволапчук И.А. Оптимизация функционального состояния детей и подростков в процессе физического воспитания: монография / И.А. Криволапчук. Гродно: ГрГУ, 2007. -606 с.

4. Лях В.И. Двигательные способности школьников: основы теории и методики развития / В.И. Лях. - М.: Терра-спорт, 2000. - 192 с.

5. Погадаев Г. Готовимся к выполнению нормативов ГТ0: 111-й классы: учебно-методическое пособие. - М.: Дрофа, 2016. - 192 с.

6. Ремшмидт Х. Подростковый и юношеский возраст: проблемы становления личности / Х. Ремшмидт. - М.: Мир, 1994. -320 c.

7. Сонькин В.Д. Развитие мышечной энергетики и работоспособности в опнтогенезе. / В.Д. Сонькин, Р.В. Тамбовцева. - М.: Книжный дом «ЛИБРОКОМ», 2011. - T.33, №3. - С.81-99.

8. Сонькин В.Д. Энергетическое обеспечение мышечной деятельности школьников: автореф. дис. ...д-ра.биол.наук: 03.00.13 / В.Д. Сонькин; НИИ физиологии детей и поростков АПН СССР. - М., 1990. - 50 с.

9. Теория и методика физической культуры / Ю.Ф. Курамшин, В.И. Григорьев, Н.Е. Латышева [и др.]; под ред. Ю.Ф. Курамшина. - М.: Советский спорт, 2007. -463 c.

10. Фарбер Д.А. Физиология школьника / Д.А. Фарбер, И.А. Корниленко, В.Д. Сонькин. — М.: Педагогика, 1990. - 64 с.

11. Физиология развития ребенка. Руководство по возрастной физиологии / Под ред. М.М. Безруких, Д.А. Фарбер. - М.: Изд-во Московского психолого-социального института, 2010. - 768 с.

12. Armstrong N. Muscle metabolism changes with age and maturation: How do they relate to youth sport performance? / N. Armstrong, A. Barker, A. McManus // Br. J. Sports Med. - 2015, 49(13), - P. 860-864.

13. Danis A. The effect of training in male prepubertal and pubertal monozygotic twins / A. Danis, Y. Kyriazis, V. Klissouras // Eur J Appl Physiol. - 2003. - Vol. 89, № 3-4. - P. 309318. 